\title{
A Case Study on the Left-behind Children Care Service with Social Organizations Involved in China
}

\author{
Yueqi Lu \\ School of Politics and Administration \\ Wuhan University of Technology \\ Wuhan, P. R. China \\ Lanbobisheng@163.com
}

\author{
Yanping $\mathrm{Yu}$ \\ School of Politics and Administration \\ Wuhan University of Technology \\ Wuhan, P. R. China \\ yanpingyu@whut.edu.cn
}

\begin{abstract}
This paper studies how social organizations in China participate in the care service of left-behind children and how to take advantage of social organization's resource to enhance the care and protection of left-behind children. Through a case study of a social organization in Hubei province, it revealed the current situation of the needed service for left-behind children, including academic counseling, parental education, guardianship care and other comprehensive education services. The study found that social organizations had fully integrated resources and combined with the advantage of social work professional, which had met the developmental demands of left-behind children efficiently. However, several limitations still existed, such as a lack of support facilities and insufficient capability. Suggestions are further put forward at the levels of government and social organizations to promote the healthy growth of left-behind children.
\end{abstract}

Keywords_left-behind children; social organization; service; case study

\section{INTRODUCTION}

Till now, the census showed there are 902 million left-behind children in rural areas in China [1]. The government takes it as high priority about the care and protection of left-behind children. The Outline for the Development of Children in China (2011-2020) points out that caring for left-behind children is a very important task. In February 2016, the State Council issued the Proposal of the State Council on enhancing the Caring and Protection of Left-behind Children in Rural Areas, in which it states about the establishment and improvements of the caring service system for left-behind children in rural areas and demands that all related government agencies should formulate effective protection policies and programs for left-behind children in rural areas. At the same time, the bureau of left-behind children protection in ministry of civil affairs was set up to formulate policies and provide guidance in the work of left-behind children protection. However, there are issues like inadequate resources and lack of coordination etc. The government functions are transformed from social management into social governance, which promotes and supports the participation of social organizations in the care of left-behind children. Social organizations have the advantages as non-profit, neutral self-government, diversified flexibility, and specialization, which become an essential complement to the national child welfare services in the care of left-behind children to promote the development of left-behind children's care [2]. These papers focuses on exploring the ways social organizations can be involved in providing care and protection to the left-behind children, discover the advantages and difficulties in their involvement, and provides strategies and suggestions based on these findings.

\section{RESEARCH METHODS}

Case study was adopted as the method in this study. We conducted a systematic study of a social organization in Huanggang, Hubei Province in China. The data was collect by the field observations and semi-structured interviews with staff members, from where we obtained the information on the practical services of left-behind children in this organization. It aims to understand how the social organizations' practical actions meet the needs of left-behind children. Also, it studies how the social organizations can care for the physical and mental health of left-behind children through the services provided. It then illustrates the advantages and needs of the improvements in services for left-behind children.

\section{RESULTS}

The case social organization, we called $\mathrm{H}$ here, is a private non-enterprise unit that has registered in Huanggang Municipal Civil Affairs Bureau of Hubei Province since July 2015. In 2017, the organization declared to the Ministry of Civil Affairs and the Ministry of Finance the approval of the Central Government's financial support for the participation of social organizations "Children's Home" under the service Class D. This service is a social work demonstration project for social services and the provision of services to left-behind children in Huangzhou District, Huanggang City in China. The organization provides services on issues such as lack of guardianship, mental health, life care, academic support and safety education for left-behind children. It applies professional methods of social work, integrates various social resources and provides multi-level services targeted on the needs of left-behind children.

\section{A. Academic Support: the "4:30 Classroom" Program}

The ARCS learning motivation model proposed by Kelly states that attention, personal, self-confidence, satisfaction are the four main factors that have an impact on students learning motivation [3]. 
To meet the needs of study tutoring of left-behind children, social organization $\mathrm{H}$ had initialized an after-school program called 4:30 class. The professional social workers created profile for each student with all basic background and academic information kept it up to date promptly. These social workers also helped to organize the voluntary tutor team from the various colleges and universities (such as Huanggang Teachers College, etc.) to help left-behind children after school at 4:30 p.m. every afternoon. These teams provided intensive homework counseling and curricular training to promote children's learning motivations. The teams established a rural left-behind children's school library to enrich the knowledge base for left-behind children through the collection of books from the community and donations of books from the society. Furthermore, these teams took left-behind children to visit historical and cultural museums stimulate children's interest in learning through the experimental teaching. They also hold competitions such as reciting, calligraphy or quiz of "Poetry of Tang and Song dynasties" to enrich the activities of academic counseling and improve the learning efficiency of left-behind children as well.

\section{B. Guardian Education Ability Enhancement: Parenting Education Program}

Parenting education refers to the education for parents of young children to be qualified, rational and responsible for raising their children [4]. Social organization $\mathrm{H}$, in the form of small group work, had carried out parenting education programs on guardianship of left-behind children and sent out a Parenting Education Handbook detailing misunderstandings in educating children's knowledge and skills for left-behind children of different ages in education. This handbook had updated guardian's educational concepts and methods, raising the awareness of guardians of left-behind children on the importance and necessity of parental education. The process enlightened the guardian to empower his or her family and gave comprehensive guidance on education methods. Psychological counseling and cultural knowledge provided a healthy environment for left-behind children at the family level. In addition, the education of left-behind children integrated with their age, psychology and personality traits enabled them to correctly understand the causes why their parents choose to relocate for work and reduce the gap between children and their parents. Carrying out "to be a well-educated child" and other small group-activities helped to promote self-care of left-behind children so that it would reduce the life burden of the guardians from generations to generations.

\section{Remote Family Communication Service}

Studies have shown that the longer the children have been left behind under the lack of parent-child relationship, the easier it is to carry psychological, safety, academic, communication and many other issues [5]. Long-term separations between left-behind children and their parents in Huangzhou have led to communication inconvenience in emotions and the single way of communication, which cause the greater demand for parent-child emotional exchanges.

The social organization $\mathrm{H}$ had established a "remote family communication window" to provide video and voice equipment for the communication of affections between left-behind children and their parents. It established a communication bridge of parent-child, ensured the frequency of communication to at least once a week, and effectively improved the quality of parent-child communication through face-to-face communication. Besides that, social workers actively understood such issues as conflicts that occur during parent-child communication time and carried out two-sided "interventions" to promote the establishment of a sound parent-child relationship. It was through the one-on-one relationship of support, family interviews at least once a week that helped social workers understand the needs of these children. Social workers took the initiative to tap the available resources for left-behind children and began to know the living environment of left-behind children. By coordinating with the class teacher, social workers ensured that the class teacher would visit each left-behind child more than once a semester to understand and guided the guardian to conduct proper family education and provide feedback as well.

\section{D. "Volunteer Mother" Services}

Social organization $\mathrm{H}$ had organized a "volunteer mom" team, which aimed to care left-behind children in a timely and effective manner. Volunteer mothers were formed by groups of left-behind women, unemployed women, full-time housewives, and female volunteer teachers. These volunteer mothers provided services, for example, the daily life care and psychological status monitoring of left-behind children. Social organization $\mathrm{H}$ had built personal profiles and offered corresponding service training for volunteer mothers. H set up the services, such as regular talk with left-behind children, to collect information on left-behind children's psychological, emotional, behavioral, healthy, social states and then uploaded the information to a guarding platform for left-behind children to supervise their status all the time. What's more, the volunteer diary books provided by $\mathrm{H}$ were to record the number of services, hours, gains and experiences, which had increased volunteers' sense of recognition and existence and had enhanced the enthusiasm of volunteer mothers in serving left-behind children.

\section{E. Challenges during the service provision}

Social organization $\mathrm{H}$ encountered some difficulties and problems in serving left-behind children. For example, government support services, policy support, government procurement mechanisms and other supporting services were very slow in the approval process. The government did not have a systematic procedure for left-behind children. Left-behind children were mostly located in rural areas; the decentralized layout increased the difficulty of political activities as well. It was also in the shortage of social work professionals. Thus, there was an urgent need to expand the social workforce. Guardians of left-behind children had low recognition in social workers, which resulted in the poor participation in service activities and ambiguous or weakening service expectations. Also, it lacked motivation for long-term service of volunteer mothers. The high turnover of service personnel and the lack of professional skills served children, to a certain extent, had restricted the service effects. 


\section{COUNTERMEASURES AND SUGGESTIONS}

\section{A. Government level}

The government should actively support social organizations to participate in the care of left-behind children and offers preferential policies on taxation, publicity and project approval to reduce the barriers for social organizations to enter the area of left-behind children's care. They also need to increase the numbers of social organizations and services that care for left-behind children and conduct the Third-Role supervision, standardize the management of social organizations. The government organizes Innovative activities for left-behind to promote the content and form of innovative services for social organizations.

Care for left-behind children has involved in many aspects, such as academic, emotional, psychological and guardian quality improvement. Government departments, can cooperate with social organizations, jointly carry out service projects according to their own resources and share information resources of left-behind children. Relevant government departments regularly consult with social organizations' process and service planning to strengthen the links between the government and social organizations. It aims to build a network of minors with the participation of local government ministries, other community-based child protection centers, other relevant government departments and social organizations as their main body. They integrate various departmental resources to support social organizations to serve left-behind children.

\section{B. Social organization level}

Social organizations should develop a diversified talent base to build a talent cooperation model with higher educations and specialized disciplines. They should also train qualified professionals in the utilization of social organizations and cultivate outstanding social workers and supervisors to provide generous benefits to social professionals. The government should strengthen the awareness of left-behind children and guardians about social organizations. Social organizations offer places to left-behind children and guardians to report the problems. They use professional working methods to help them solve their demands and life problems. They set up resource information platforms for left-behind children to link with the government, and social resources, thereby enhancing the recognition and trust of social organizations from left-behind children and their guardians.

Based on field investigation of the layout of left-behind children. Social organizations set up social service stations according to the concentration of left-behind children and the convenience of participating in services, reduce the size of service targets and increase the frequency of holding venues and services. It innovates comprehensive, personalized services and multi-Service advantages of the new service. Strengthen the continuous training on volunteer mom's serviceability, and social workers guide on-site volunteer mom to serve left-behind children. Meet regularly to communicate service difficulties, share effective experience to improve the service level of volunteer mom, and build stable and professional volunteer mom team. Volunteer mothers should be rewarded for their services provided.
The government has provided double guarantees of the system and material for the care of left-behind children, but there is a potential problem of inadequate regulations and market failures. Social organizations are necessary to participate in the care of left-behind children [6].Social organizations should act as a bridge between the government and left-behind children to assist the government in carrying out the work of left-behind children and provide channels for service and help for left-behind children. Social organizations can assist the government in establishing basic information files on the family circumstances and development needs of left-behind children and provide information support for left-behind children. Assist the government in implementing supportive work for left-behind children, subsidize relevant welfare subsidies and implement the government's guidelines and policies. The government's advocacy of helping left-behind children has gained a better understanding of the government's policies in supporting left-behind children and put forward their own development needs.

\section{SUMMARY}

The Chinese government encourages social organizations to take an active role in the protection of left-behind children, and provides political and financial support, which have greatly promoted the participation of social organizations in the care of left-behind children. Based on the development needs of left-behind children, the effective integration of volunteer resources, government support, and other social resources, Social organization $\mathrm{H}$ has successfully carried out care services for left-behind children. It is to solve the left-behind children academic counseling, lack of custody, parent-child exchange difficulties and promote healthy growth of left-behind children. Social organizations are necessary to participate in the care of left-behind children. However, social organizations encounter difficulties and problems in serving left-behind children. Both the government and social organizations should jointly devote effort to provide professional and comprehensive services for left-behind children in China.

\section{REFERENCES}

[1] The Ministry of Civil Affairs. (2016). Report on Left-behind Children in rural areas in China and the Care Protection of the Ministry of Civil Affairs. (In Chinese)

[2] Zhang, Z. (2014). Social Organization study on left-behind children in rural areas in China. Special Zone Economy, 06, 159-160(In Chinese).

[3] Y. W. Sek,E. Mckay,H. Deng. (2016).The effect of learning preferences on learners' motivations: Towards an ARCS motivational design in open learner models. E-learning, E-management \& E-services.52-57.

[4] J. J. Ponzetti. (2016), Evidence based parenting education: A global perspective. Taylor \& Francis Ltd.

[5] Wu, Z., \& Li, J. (2015). Report on the current situation of Left-behind children. Journal of China Agricultural University (Social Sciences Edition, 32(01), 65-74(In Chinese).

[6] Lu, S., \& Sun, R. (2013). Social Organization and assistance in street children and left-behind Children. Journal of Guangxi Youth Leaders College, 24(6), 21-25(In Chinese). 